Artikel Penelitian

\title{
Green Synthesis Senyawa Imina dari Vanillin and Anilina dengan Katalis Alami Air Jeruk Nipis (Citrus aurantifolia)
}

\author{
Nurush Shofi al Hakimi, Ahmad Hanapi*, Ahmad Ghanaim Fasya \\ Jurusan Kimia, Fakultas Sains dan Teknologi, Universitas Islam Negeri Maulana Malik Ibrahim Malang, Indonesia
}

INFO ARTIKEL

Sejarah artikel:

Revisi 15 Oktober 2017

Diterima 30 Oktober 2017

Tersedia online 16 Januari 2018

*Penulis korespondensi

Email: chanafi_achmad@yahoo.com

\begin{abstract}
ABSTRAK
Synthesized imine from vanillin and aniline was conducted with solvent-free by adding natural catalyst lime juice (Citrus aurantifolia). This research focused on characterization of imine product using variation of lime juice volume $(0.5,1.0,1.5,2.0$ and $2.5 \mathrm{~mL})$. Imine product was characterized based on shape, color, melting point and yield. The product was also identified by FITR and GCMS. P1 was e highest yield and purity of imine product were $64.12 \%$ and $74.74 \%$, respectively. Physical characterization of imine product was solid form and yellow color with melting point of $150^{\circ} \mathrm{C}$.GCMS spectra showed target compound has formed $\mathrm{m} / \mathrm{z} 227\left(\mathrm{M}^{*}\right)$ that referred to 2-metoxy-4-((phenylimino)methyl)phenol. IR spectra confirmed presence of target compound in specific wavelength of imine $(\mathrm{C}=\mathrm{N})$ at $1584 \mathrm{~cm}^{-1}$.
\end{abstract}

Keywords: imine, vanillin, aniline, lime juice, catalyst

\begin{abstract}
Sintesis imina dari vanilin dan anilina dapat dilakukan tanpa pelarut dengan bantuan katalis asam alami dari jeruk nipis (Citrus aurantifolia). Penelitian ini bertujuan untuk mengkarakterisasi produk imina dengan variasi volume katalis jeruk nipis. Volume katalis jeruk nipis yang digunakan adalah 0,5; 1,0; 1,$5 ; 2,0$; dan $2,5 \mathrm{~mL}$. Produk imina dikarakterisasi berdasarkan bentuk, warna, titik lebur dan rendemen. Produk juga identifikasi menggunakan FTIR dan KG-SM. Sintesis imina menghasilkan P1 sebagai produk terbaik dengan rendemen sebesar $64,12 \%$ dan tingkat kemurnian $74,74 \%$. Hasil karakterisasi produk imina berupa padatan yang berwarna kuning dengan titik lebur $150^{\circ} \mathrm{C}$. Hasil KG-SM menunjukkan adanya senyawa target sintesis 2-metoksi-4-((fenilimino)metil)fenol pada $\mathrm{m} / \mathrm{z} 227 \quad\left(\mathrm{M}^{*}\right)$. Terbentuknya senyawa target diperkuat dengan spektra IR khas senyawa imina $(C=N)$ pada $1584 \mathrm{~cm}^{-1}$.
\end{abstract}

Kata Kunci: imina, vanilin, anilina, air jeruk nipis, katalis

\section{Pendahuluan}

Imina merupakan salah satu senyawa basaSchiff yang banyak disintesis karena luas aplikasinya. Senyawa ini berpotensi sebagai antioksidan, antimikroba, dan antiinflamasi. Selain itu, senyawa imina dapat juga digunakan sebagai indikator asam-basa (Vibhute, Zangade, Chavan, \&
Vibhute, 2011; Purwono, Anwar, \& Hanapi, 2013). Imina merupakan prekusor dari berbagai jenis obat seperti obat penenang, obat bius, dan obat kontrasepsi (Vibhute et al., 2011).

Senyawa basa-Schiff dapat disintesis melalui reaksi adisi-eliminasi antara senyawa aldehida dengan suatu amina primer. Secara konvensional, 
senyawa ini dibuat dengan merefluks campuran aldehida/keton dengan amina primer dalam pelarut organik volatil. Proses sintesis dilakukan dengan penambahan katalis asam (Fessenden \& Fessenden, 1982). Purwono, et al. (2013) mensintesis senyawa imina dari vanillin dan anilina menggunakan pelarut etanol dengan teknik refluks dengan rendemen sebesar $82,17 \%$.

Pembuatan suatu senyawa organik dapat dilakukan melalui metode green synthesis. Metode tersebut merupakan salah satu sintesis yang tidak menggunakan pelarut dalam proses reaksinya. Adapun beberapa kelebihan green synthesis adalah ekonomis, mudah, ramah lingkungan dan efisien. Sintesis senyawa imina dapat dilakukan dengan beberapa metode yaitu melalui metode penggerusan (Rahman, Ali, Jahng, \& Kadi, 2012), penggunaan pelarut air (Naqvi, Shahnawaaz, Rao, Seth \& Sharma 2009), dan penggunaan katalis asam alami (Patil, Jadhav, \& Deshmukh, 2011a; Patil, Jadhav, \& Patil, 2012). Sintesis beberapa senyawa imina dilakukan dengan bantuan katalis air lemon dan menghasilkan produk imina sebesar 72-100\% (Patil et al., 2011a; Patil et al., 2012). Patil, Jadhav, \& Mane (2011b) juga menggunakan air nanas sebagai katalis alami pada reaksi Biginelli.

Penerapan metode green synthesis merupakan salah satu upaya untuk mengembangkan metode sintesis yang ramah terhadap lingkungan. Pada penelitian ini akan disintesis senyawa turunan imina dari vanilin dan anilina dengan katalis alami air jeruk nipis dengan variasi volume katalis.

\section{Bahan dan metode}

\subsection{Bahan}

Penelitian ini menggunakan vanilin f.s (Merck), anilina f.s (Merck), air jeruk nipis dan plat KLT $\mathrm{G}_{60} \mathrm{~F}_{254}$.

\subsection{Sintesis senyawa imina dengan variasi volume katalis air jeruk nipis}

Senyawa anilina 0,9313 gram $(10 \mathrm{mmol})$ direaksikan dengan vanillin 1,5215 (10 mmol). Kemudian, ditambahkan $0,5 \mathrm{~mL}$ air jeruk nipis sebagai katalis. Campuran diaduk selama 30 menit hingga terbentuk padatan kuning. Perlakuan tersebut diulangi pada variasi volume katalis 1,0 ; 1,$5 ; \quad 2,0$ dan 2,5 mL. Reaksi dimonitoring menggunakan plat KLT. Padatan yang terbentuk dimurnikan dengan proses rekristalisasi.

\subsection{Karakterisasi produk}

Produk dikarakterisasi berdasarkan sifat fisik yang meliputi wujud, warna, titik lebur dan rendemen. Produk diidentifikasi lebih lanjut menggunakan spektrofotometer FTIR (Varian tipe FT 1000) dan KG-SM (QP2010S Shimadzu).

\section{Hasil dan pembahasan}

\subsection{Karakteristik produk imina}

Produk imina yang dihasilkan menunjukkan karakteristik yang hampir sama. Berdasarkan Tabel 1, titik leleh kelima produk berkisar antara 150$152^{\circ} \mathrm{C}$. Perbedaan terjadi pada warna produk, dimana P1 menghasilkan padatan kuning, sedangkan P2-P5 menghasilkan padatan kuning kecoklatan. Warna kuning kecoklatan ini dimungkinkan karena adanya sisa anilina yang tidak bereaksi. Karakteristik wujud, warna dan titik lebur yang diperoleh sesuai dengan sifat fisik dari senyawa 2-metoksi-4-((fenilimino)metil)fenol yang telah berhasil disintesis Purwono et al. (2013).

Penambahan volume katalis air jeruk nipis pada proses sintesis menurunkan massa produk (Tabel 1). Hal ini terjadi karena semakin bertambahnya katalis asam akan membuat amina menjadi terprotonasi dan menurunkan kekuatannya sebagai nukleofil (Yadav \& Mani, 2015).

Tabel 1.

Karakterisasi sifat fisik produk imina

\begin{tabular}{cccccc}
\hline \multirow{2}{*}{ Produk } & \multicolumn{3}{c}{ Sifat Fisik } & Massa & $\begin{array}{c}\text { Rendemen } \\
\text { (gram) }\end{array}$ \\
\cline { 2 - 3 } & Wujud & Warna & Titik Lebur $\left({ }^{\circ} \mathbf{C}\right)$ & \\
\hline P1 & Padatan & Kuning & 150 & 1,459 & 64,12 \\
P2 & Padatan & Kuning Kecoklatan & 152 & 1,386 & 60,98 \\
P3 & Padatan & Kuning Kecoklatan & 150 & 1,104 & 48,58 \\
P4 & Padatan & Kuning Kecoklatan & 152 & 0,928 & 40,85 \\
P5 & Padatan & Kuning Kecoklatan & 152 & 0,838 & 36,82 \\
\hline
\end{tabular}

Keterangan: $P=$ Produk. Volume katalis pada $P 1, P 2, P 3, P 4$, dan $P 5$ masing-masing adalah 0,5; 1,0; 1,5; 2,0; dan 2,5 mL. 
Tabel 2.

Hasil spektra IR produk imina

\begin{tabular}{lccccc}
\hline \multirow{2}{*}{ Gugus Fungsi } & \multicolumn{5}{c}{ Bilangang gelombang, $\overline{\mathbf{v}}\left(\mathbf{c m}^{-1} \mathbf{)}\right.$} \\
\cline { 2 - 6 } & $\mathbf{P 1}$ & $\mathbf{P 2}$ & $\mathbf{P 3}$ & $\mathbf{P 4}$ & P5 \\
\hline$-\mathrm{OH}$ & $2800-3400$ & $2800-3400$ & $2800-3400$ & $2800-3400$ & $2800-3400$ \\
$\mathrm{C}-\mathrm{H}(\mathrm{sp} 2)$ & 3091 & 3089 & 3086 & 3089 & 3086 \\
$\mathrm{C}=\mathrm{C}$ aromatik & 1515 & 1515 & 1515 & 1516 & 1515 \\
$\mathrm{C}-\mathrm{H}(\mathrm{sp} 3)$ & 2935 & 2937 & 2937 & 2938 & 2937 \\
Metil $\left(-\mathrm{CH}_{3}\right)$ & 1428 & 1428 & 1428 & 1428 & 1428 \\
Eter $(\mathrm{C}-\mathrm{O}-\mathrm{C})$ & 1285,1030 & 1285,1030 & 1285,1030 & 1285,1030 & 1285,1030 \\
(-C=N-) & 1584 & 1584 & 1584 & 1584 & 1584 \\
Aromatik tersubtitusi & 876,813 & 876,812 & 875,812 & 876,813 & 875,812 \\
\hline
\end{tabular}

\subsection{Karakterisasi produk dengan FTIR}

Hasil karakterisasi dengan FTIR menunjukkan bahwa kelima produk memiliki berbagai pita serapan pada bilangan gelombang yang hampir sama (Tabel 2). Tidak munculnya pita serapan kuat gugus karbonil $(-\mathrm{C}=0)$ dari senyawa vanilin pada bilangan gelombang $1666 \mathrm{~cm}^{-1}$ dan munculnya pita serapan baru pada bilangan gelombang $1584 \mathrm{~cm}^{-1}$ mengindikasikan bahwa produk imina telah terbentuk. Pita serapan baru pada bilangan gelombang $1584 \mathrm{~cm}^{-1}$ tersebut merupakan serapan khas dari gugus imina $(-\mathrm{C}=\mathrm{N})$.

\subsection{Karakterisasi Produk dengan KG-SM}

Karakterisasi dengan KG-SM dilakukan pada produk dengan nilai rendemen tertinggi (volume katalis $0,5 \mathrm{~mL}$ ). Terdapat empat puncak pada kromatogram (Gambar 1(a)). Puncak ini yang menunjukkan bahwa P1 mengandung empat senyawa. Berdasarkan pola fragmentasi data SM dan dibantu dengan penelusuran library dapat diketahui bahwa puncak 1, 2 dan 3 secara berturutturut adalah senyawa anilina, by product, dan vanilin. Senyawa produk muncul sebagai puncak 4 dengan waktu retensi 41,57 menit dan persentase luas area atau kemurnian berdasarkan KG sebesar $74,74 \%$.
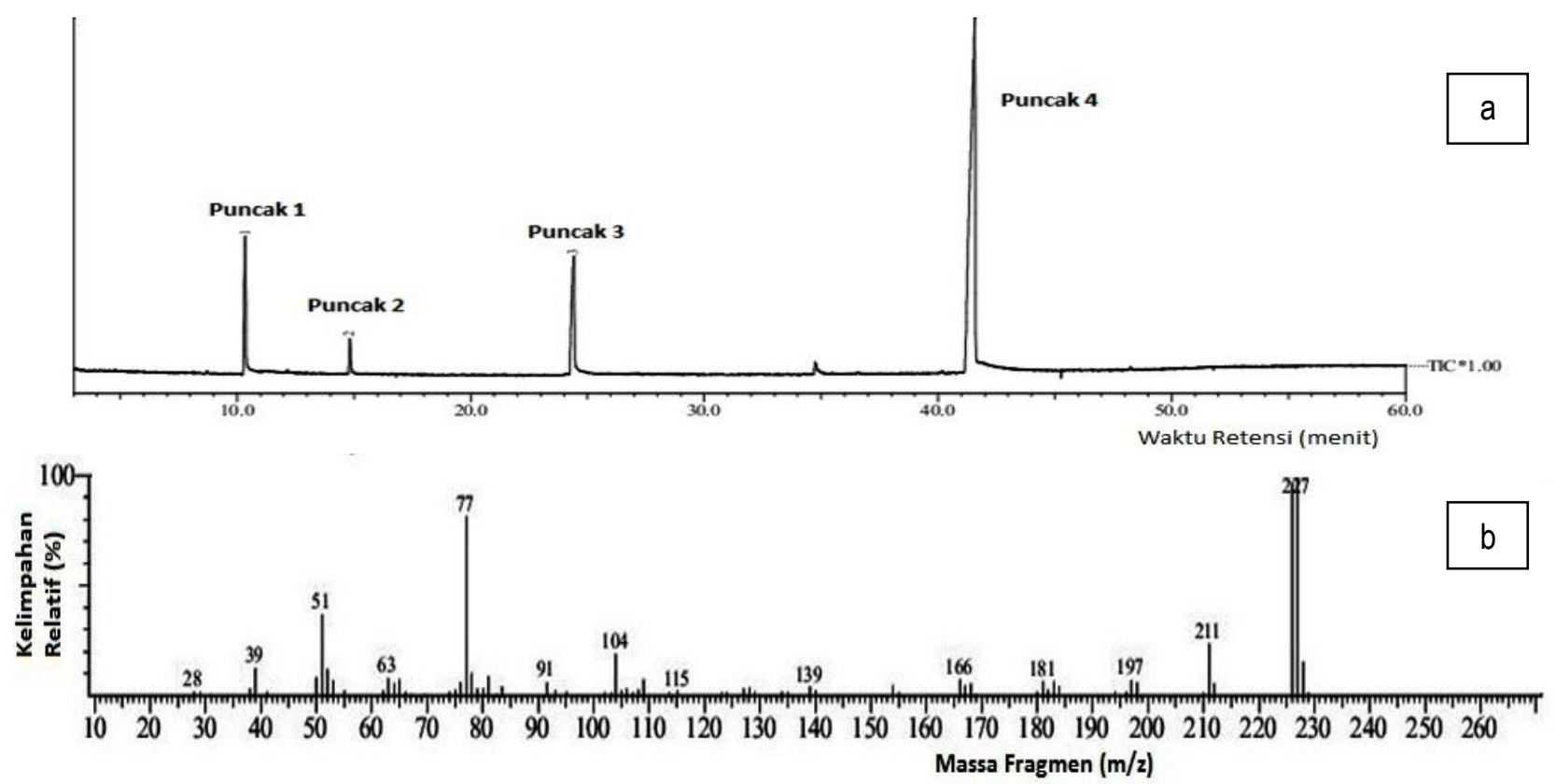

Gambar 1. (a). Kromatogram hasil analisis KG pada P1, dan (b). Spektra massa pada puncak 4 
Berdasarkan spektra massa produk (puncak 4) dapat dilihat bahwa nilai $\mathrm{m} / \mathrm{z} 227$ dengan kelimpahan relatif sebesar $100 \%$ merupakan puncak dasar sekaligus puncak ion molekuler. Nilai $\mathrm{m} / \mathrm{z}$ tersebut sesuai dengan berat molekul senyawa target sintesis yaitu 2-metoksi-4((fenilimino)metil)fenol. Pola fragmentasi yang tersaji pada Gambar 2 juga menguatkan dugaan bahwa puncak 4 merupakan senyawa target sintesis.

\section{Kesimpulan}

Volume katalis air jeruk nipis terbaik dalam pembentukan imina adalah $0,5 \mathrm{~mL}$. Produk ini menghasilkan sifat fisik berupa padatan kuning dengan titik lebur $150^{\circ} \mathrm{C}$. P1 memberikan nilai rendemen terbaik sebesar $64,12 \%$ dan kemurnian sebesar $74,74 \%$. Produk memiliki spektra IR khas senyawa imina $(C=N)$ pada $1584 \mathrm{~cm}^{-1}$. Spektra massa $\mathrm{m} / \mathrm{z} 227\left(\mathrm{M}^{*}\right)$ muncul sebagai puncak ion molekuler senyawa target sintesis 2-metoksi-4((fenilimino)metil)fenol.

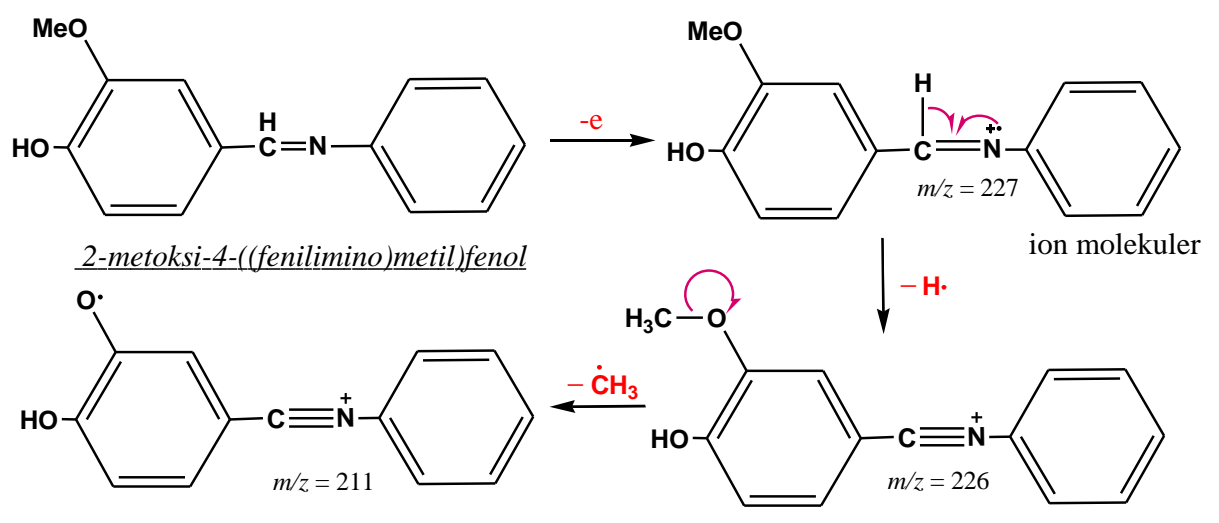

Pola fragmentasi I:


Pola fragmentasi II:
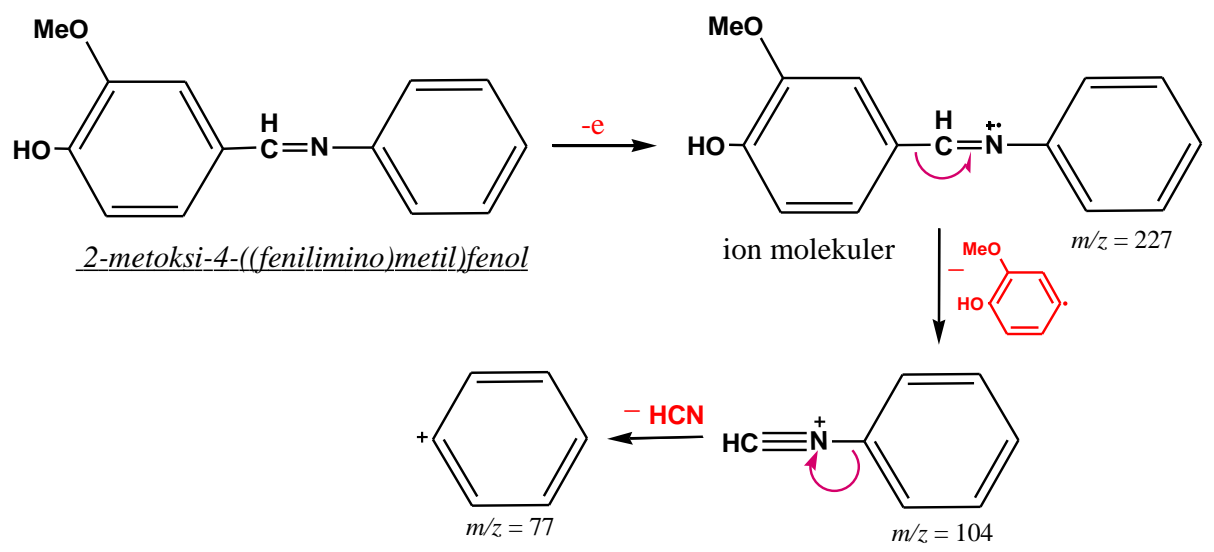

Gambar 2. Pola fragmentasi senyawa 2-metoksi-4-((fenilimino)metil)fenol 


\section{Daftar pustaka}

Fessenden, R.J., \& Fessenden, J.S. (1982). Kimia Organik Jilid 2 (Edisi ke-3). (A.H. Pudjaatmaka, Terjemahan). Jakarta: Erlangga.

Naqvi, A., Shahnawaaz, M., Rao, A.V., Seth, D.S., \& Sharma, N.K. (2009). Synthesis of Schiff bases via environmentally Benign and energy-efficient greener methodologies. EJournal of Chemistry, 6(S1), S75-S78.

Patil, S., Jadhav, S.D., \& Deshmukh, M.B. (2011a). Natural acid catalyzed multi-component reactions as a green approach. Archives of Applied Science Research, 3(1), 203-208.

Patil, S.; Jadhav, S.D., \& Mane, S.Y. (2011b). Pineapple juice as a natural catalyst: an excellent catalyst for Biginelli reaction. International Journal of Organic Chemistry, 1(3), 125-131.

Patil, S., Jadhav, S.D., \& Patil, U.P. (2012). Natural acid catalyzed synthesis of Schiff base under solvent-free condition: as a green approach. Archives of Applied Science Research, 4(2), 1074-1078.
Purwono, B., Anwar, C., \& Hanapi, A. (2013). Syntheses of azo-imine derivatives from vanillin as an acid base indicator. Indonesian Journal of Chemistry, 13(1), 1-6.

Rahman, A.F.M.M, Ali, R., Jahng, Y., \& Kadi, A.A. (2012) A facile solvent free Claisen-Schmidt reaction: synthesis of a,a'-bis-(substitutedbenzylidene)cycloalkanones and $a, a^{\prime}$-bis (substituted-alkylidene)cycloalkanones. Molecules, 17(1), 517-583.

Vibhute, A.Y., Zangade, S.B., Chavan, S.B., \& Vibhute, Y.B. (2011). A one pot synthesis of 1,3-benzoxazines from Schiff's bases. Der Pharmacia Sinica, 2(5), 2017-222.

Yadav, G dan Mani, J.V. (2015). Green synthesis of Schiff bases by using natural acid catalysts. International Journal of Science and Research, 4(2), 121-127. 